mediebrug ved bl.a. at kritisere elevernes reproduktioner af velkendte genrer (fx. western-parodier), tager gruelig fejl, skriver Kirsten Drotner. Sa tager vi medielerere nemlig udgangspunkt i modernismens avantgarde-astetik og afviser noget, der er langt vasentligere for de unge $i$ deres udvikling, nemlig: deres falles grin, deres afprovning af sig selv og af deres omverdensforhold.

Nye - farbare? - veje 1 medieundervisningen ses ogsa $i$ de folgende fem artikler, samlet under fallestitlen: "Om forsфgsarbejde ned medieundervisning". Birgitte Holm Sorensen og Hans Cornelius beskriver og evaluerer fors $\phi 9$ inden for seminarierne. Jette Tybjerg, Povl Erik Brondgaard og ole Weischer redegør for erfaringer fra gymnasie- og HF-omadet. De ex enige om betydningen af det praktiske mediearbejde, men enigheden holder op, nax de skal placere medieundervisningen inden for skolesystemet: Skal vi have et mediefag? skal medieundervisningen tages ind $i$ danskundervisningen $i$ storre omfang? skal medieundervisningen placeres inden for bestemte faggrupper? Skal en specialuddannet medielarer fungerer som gæstelarer i forskellige fag? Medieproduktion pa amatфrbasis findes som bekendt ikke kun inden for undervisningsomradet. Hvad skal vi bruge videovarkstederne til? spørger Tove Heidemann i artiklen, der afslutter nummeret.

Redaktionen 


\section{Den mediepædagogiske udfordring}

\section{Af Jørgen Bang}

I denne kopte artikel advarer Jprgen Bang mod, at undervisningen $i$ medier skal vende tilbage til den afotandstagende indholdskritik. Det sker Bl.a. under indtryk af Neil Postman's danske udgave af 'Amusing Ourselves. to Death'.

Hans synspunkt ex, at receptionsforskningens spede forsog pa at foreto elevernes mediebrug bor fastholdes, hvis medieundervisningen skal have nogen samfundsmessig funktion.

I dette foråx udkom på dansk Neil postman's bog on TV-mediets negative indflydelse på vores kultur. Titlen 'Fagre nye TV-verden' ex en direkte henvisning til Huxley"s roman "Fagre nye verden" Postman deler Huxley's visioner om, at vi ex ved at miste vores selvbestemmelsesret og dommekraft. Det er lkke 'Big Brother" som iagttager os, men med TV ex Vi $i$ fard med at more os selv ihjel - hvad bogen $i$ ovigt hedder pa amerikansk *

Neil Postmann skxiver sig med denne bog ind $i$ en pessimistisk kulturkritisk tradition, som ogsa rummer Jerry Mander og hans fire argumenter for at afskaffe TV, samt Hans Magnus Enzensberger, der karakteriserer TV som et nulmedie med total indholds-og betydningsløshed.

Blandt de mange, som underviser og forskex 1 medier og komunikation, fordi de finder området vasentligt både 1 en padagogisk og 1 en samfundsmassig sammenhang, ex en bog som Postman's blot et kuri申st indslag. Men for de gamle kulturradikalere og de borgerlige kunstdyrkexe, som finder, at undervisningen $i$ massekommunikation 
er et knafald for fordumnelsen og den darlige smag, er bogen et yderligere argument for omradets farlighed og underlodighed.

Med Postman i hånden vil de bruge undervisningen i TV-mediet til at påpege teksternes simple og populistiske tilsnit i kontrast til de kunstneriske teksters iboende kontemplation. Tesen om TV's fordumende virkning vil blive bekraftet $i$ undervisningen og afstanden til elevernes mediebrug $i$ det daglige vil blive storre og storre. Den aristokratiske dannelsestankning, som mere end noget andet satter laxernes position som kulturbarere til skue, vil igen blive dominerende. De spade mediebrug hos eleverne vil blive erstattet af en normativ smagsastetik, der skal indlares med eller mod de sociaLe tilhorsforhold. Medieteksten og ikke tilegnelsen vil vare $i$ centrum for undervisningen.

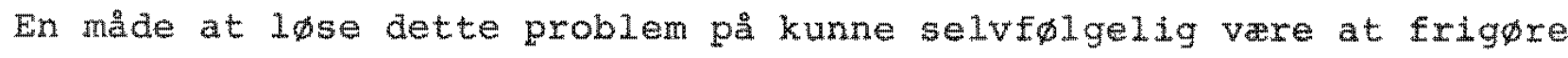
undervisningen i mediex fra danskundervisninge. Den kunne gфres til et selvstandigt fag med egne larere med overvejende sociologisk uddannelse. Derved ville fokus blive flyttet fra teksten til modtagerne og hovedvagten lagt pa mediernes funktion 1 samfundet. Men samtidig ville det kulturelle perspektiv pa den menneskelige menings- og betydningsdannelse blive kraftig reduceret, dvs. at et makro-perspektiv ville komme til at dominere over et mikro-perspektiv.

Jeg finder det vigtigt at fastholde undervisningen i massekommunikation og popularkultur som et aktuelt kulturfag, hvor det er socialisationen og den samfundsmassige integration, der star i centrum. Indtil videre tror jeg dette bedst gores i danskundervisningens regi i samarbejde med undervisningen i litteratur, sprog og sagsprosa - selv on dette samarbejde netop lagger op til en kulturpolitisk konflikt.

Den nyere receptionsforskning har tilvejebragt nogle indsigter i selve tilegnelsesprocessen, der dels udstikkes rammerne for en fornyet mediepadagogisk diskussion, dels sattes et nyt refleksionsrum for kulturdiskussionen og underviserens kritiske mediebevidsthed. 
Modtagerens tekst ex ikke en mere eller mindre rigtig gengivelse af afsenderens tekst ellex af teksten slet og ret, men ex en selvstandig bearbejdelse i dialog med hans/hendes hele Iivsammenhang. Den del af medieundervisningen, som ikke satser på kundskab om medierne og deres samfundsmessige funktion, men pă oparbejdelse af en kritisk mediebevidsthed hos eleverne, må derfor tage udgangspunkt i modtagernes subjektive erfaringer med tilegnelsen. Og det er lkke resultaterne af afkodningen, som skal bearbejdes, men selve thlegnelsesprocessen: Hvilke elementer i teksten er det modtageren/ eleven knyttex af til? Hvordan knyttes der an? Hvor knyttes der an? Modtageren/eleven skal bevidstgøres on de sociale og psykologiske betingelser for tilegnelsen og dens tekstuelle afhengighed.

Selve princippet at tage udgangspunkt i elevernes erfaringer kendes fra exfaringspadagogikken. Eleverne gør nogle konkrete frigørende erfaringer, som fastholdes og bevidstgфres i undervisningen. Der ex overensstemmelse mellem larerens progressive selvforståelse, stoffets hverdagsrelevans og elevernes horisont. Problemet er imidlertid, at denne samenhang mangler i forhold til massekommulkation og popular kultur.

Et skift i fokus fra teksten til modtageren forudsatter en mndret kultuxforstaelse hos larerne i danskfaget. Det klassiske humanism tiske kulturbegreb, at kulturen er synonym med de mest originale og ypperligste kunstneriske frembringelser, må erstattes af et antropologisk, der forstăr kultur, som den totale livssammenheng 1 et givet samfund (Williams (1958)).

Det betyder ikke, at lareren skal gore elevernes medieerfaringer til sine, men han/hun ma forholde sig abent og anskue hele brugen af savel litteratur som af massekommunikation og popular kultux som en del af livssammenhangen i sin helhed. Pa det samfundsmassige niveau er de medieformidlede tekster med til at skabe sammenhang og intersubjektiv forstålse $i$ og med, at de pa det individuelle niveau - og det galder isar for litteraturens og populærkulturens vedkommende - giver laseren/lytteren/seeren og altsa eleven mulighed for at bearbejde egne erfaringer, oplevelser, fantasier, dromme, længslex, håb m.m. på en sanselig og narvarende måde. 
Ernst Bloch (1954-59) påpeger, at dagdrommen er utopiens latente vakstpunkt, at langsel og håb vokser ud af mangel og utilfredshed, samt at folkelige forlystelser som gøgl, clrkus, eventyr, viser og 'historier' indeholder kritiske elementer, som rummer utopiske momenter. Nar leseren/lytteren/seeren bruger en medieformialet tekst til at bevage sig udover sin faktiske situation og forestille sig andre tilstande, kan det have karakter af dagdrommeri, men indeholder altsa samtidig et latent behov og en 'skjult' kritik.

Undervisningens opgave mä vare at fremdrage disse behov og bearbejde denne kritlk, så laseren/lytteren/seeren og altsa eleven bliver bevidstgjort on dem, ikke med henblik pa et 'bedre' tekstvalg neste gang, men for at kunne handle samfundsmassigt adakvat.

I denne situation har en nedvurdering af massekommunikationen og populær kulturen den stik modsatte virkning. Derfor kan Neil postman's bog maske vise sig at vare benzin pa et ulmende bal, isar 1 dette land, hvor vores undervisningsminister sex med skepsis pä ethvert brud på den traditionelle kulturformidling.

\section{LITIERATUR}

Bang, Jprgen (1988): 'Modtagerforskning oq kulturstudier', in: Mediekultux I, 1988 \& Nordicom-Information 3, 1988.

Bloch, Exnst (1954-59): Das Prinzip Hoffnung, Suhrkamp, 1976.

Bourdieu, Pierre (1979): Distinction. A Social Critique of the Judgement of

Taste, Routledge \& Kegan Paul, London, 1984 (fransk org. 1979).

Enzensbergex, Hans Magnus (1988) 'Nulmediet. Eller: Hortor alle klager ovex fjexnsynet er formalslose" In: Fredag, nr. 18, 3. arg. 1988.

Garnham, Nicholas (1987): 'Kulturnationalisme og internationalisme in:Mediekultux $5,87$.

Hall, Stuart (1973): 'Encoding and Decoding in the Television Message", in:

5. Hall et al.: Culture, Media, Language, Hutchinson, London, 1980.

Mander, Jerry (1977): Fixe argumenter for at afskaffe TV, Kbh. 81, (am.org. 1977).

Mastemann. Len (1985): Teaching the Media, Gomedia, London, 1985.

Postman, Neil (1985): Fagre nye TV-verden, Hekla, 1989 (am.oxg. 1985).

Williams, Raymond (1958): Culture and Society: 1780-1950, London, 1958.

Jørgen Bang er lektor ved Institut for informations- og medievidenskab, Arhus Universitet. 


\section{At konstruere et TV-program}

\section{Af Henrik Poulsen}

I Danmanks Radio har man siden 1982 uddannet TV-produktionsmedarbejdere ud fra ét bestemt cestetiak koneept, der i daglig tale kaldes for TV-SUM. Koneeptet er sammensat af tearier og analyometoder fra vidt forskeltige faglige dicipliner og traditioner i et - ved forste ojekast - konsiatent og produktionsklart system. Henrik poulsen har kigget nermere pi dette system og gennemgar i denne artiket dets vigtigste elementer med Baadsgaards 'Spforkzaring' som eksempel. I tizknytning hertil vurderer han suM-materialets anvendelighed $i$ medieundervisningen samt trekker enkelte af de begrebsmessige urimeligheder frem, som konceptet - trods sin besncrende logik indehozder.

\section{TV-SUM som TV-produktionens topnфgleset}

TV-SUM er et velkendt begreb indenfor murene i Danmarks Radio. Begrebet ackker over en rakke kursusforlфb, der henvender sig til alle $i$ DR, som er beskxftiget med TV-produktion - teknikere, programmedarbejdere, dekorationsfolk, producere osv. TV-SUM stăr for TV-Som-Udtryksmiddel, og i de 7-8 ăr kurserne har eksisteret, har forkortelsen varet omfattet af en serlig eufori blandt de producerende medarbejdere. Det ex også noget sarligt. Hovedparten af DRs kursusvirksomhed for egne medarbejdere ex nemlig tekniske og funktionsbestemte kurser, der er rettede mod bestemte faglige grupper og mod bestemte faglige problemer - kursus i en-kameraproduktion, kursus i paintbox osv. Hex er så et kursus - TV-suM - der beskæftiger sig med det, som udenforstånde matte trokom forst, nemlig med TV-mediets særilge udtryksmuligheder, med dramaturgi, med billedxstetik, med produktionsdesign fra ide til produktion osv. 